\title{
PRACTICE OF INFORMATION TECHNOLOGY IN TRANSLATION TEACHING AT CHINESE REGIONAL UNIVERSITIES IN THE ERA OF ARTIFICIAL INTELLIGENCE
}

\author{
Ma, Yan, ${ }^{\mathrm{i}}$ \\ Wang, Feng \\ School of Foreign Studies, \\ Yangtze University, \\ Hubei Province, 434023, \\ P. R. China
}

\begin{abstract}
:
With its rapid development in recent years, artificial intelligence has been widely used in all aspects of our life, including language teaching and learning. After a review of the history of artificial intelligence technology and a discussion of the development of artificial intelligent translation at home and abroad, the article summarizes the characteristics of translation teaching at Chinese regional universities in the era of artificial intelligent and puts forward pedagogical suggestions for the reform and innovation in translation teaching.
\end{abstract}

Keywords: artificial intelligence, translation teaching, Chinese regional universities

\section{Introduction}

In recent years, the accelerating advancement of science and technology makes artificial intelligence an inevitable trend of the time and some major breakthroughs have been made in this new field. Now the new algorithms, experiences and applications of artificial intelligence are indispensable in people's daily life, playing an increasingly important role in the development of human society.

Nowadays, artificial intelligence, as a new world-wide focus and a key factor in enhancing China's international competitiveness, has been highly valued by the Chinese government. In the New Generation of Artificial Intelligence Development Plan (State Council, 2017), it is proposed to develop an artificial intelligent emerging industry and seek for intelligent system solutions, such as image recognition, speech recognition, machine translation, intelligent interaction, and knowledge processing.

i Correspondence: email helencn86@126.com 
It has been clearly pointed out in the Three-Year Action Plan for Promoting the Development of a New Generation of Artificial Intelligence Industry (2018-2020) issued by the Ministry of Industry and Information Technology to develop the intelligent translation industry and promote the application of high-precision intelligent translation systems for the improvement of accuracy and usability in multilingual translation and simultaneous interpretation (Ministry of Industry and Information Technology of China, 2017).

The Ministry of Education in 2018 issued the Innovative Action Plan for Artificial Intelligence in Colleges and Universities (Chinese Ministry of Education, 2018), clearly stating that speeding up the innovation application of artificial intelligence in the field of education, making use of smart technology to support the innovation of the personnel training mode, helping the reforming teaching methods, improving the educational governance ability, and constructing an intelligent, networked, personalized lifelong educational system are important ways and indispensable driving forces to promote a balanced education development as well as to realize education quality, equity and modernization.

It is obvious that artificial intelligence is striving into the field of education, whose rapid development will undoubtedly bring new opportunities, challenges and changes to foreign language teaching and learning. Under the background of artificial intelligence, the development of disciplines will experience a new phase when tradition integrates with technology, and the innovation of knowledge develops in parallel with that of technology (He Liubo, 2018). With the help of artificial intelligence technology, translation teaching will turn a completely new page.

\section{The development of artificial intelligence translation}

Artificial intelligence (abbreviated AI) was proposed by John McCarthy in 1956, marking the birth of the artificial intelligence discipline. Artificial intelligence mainly studies artificial methods and techniques. It realizes machine intelligence through imitating, extending and expanding human intelligence. Artificial intelligence has experienced three stages of development: computational intelligence, perceived intelligence and understanding intelligence (Zhang Ailing et al., 2018)

Artificial intelligence translation is to translate a written or sound form of a natural language into another written or sound form of another natural language based on a specific computer program which combines the knowledge of computer linguistics, artificial intelligence and mathematical logic. Artificial intelligence translation is an intelligent ecosystem built by the Internet, people involved and the machine (Liang Jianwei, 2018)

Artificial intelligence translation is the product of the continuous development of machine translation. The process of machine translation is roughly divided into three stages: original analysis, original translation conversion and translation generation. The applications of machine translation include information acquisition, information release and information exchange, among which information acquisition is relatively mature and 
widely used at present. And the close combination of computer-assisted translation (CAT) technology and machine translation which aims at information release has become an indispensable tool for professional translators and interpreters. Machine translation for the purpose of information exchange is mainly used for speaking, travelling and text chatting. Although its research is in profusion currently, it has not yet reached the maturity in large-scale applications (Zhang Ailing et al., 2018).

Machine translation technology has undergone incessant evolution and upgrading. At first, it was the rule-based translation system which experienced its development from vocabulary-based, grammar-based, and semantic-based to intelligence-based, producing three main translation methods: literal translation, transformational translation and inter-lingual translation. It then evolved into a statistical-based translation system, which constructed a translation model after a statistical analysis of a parallel corpus to translate a natural language into another natural language. However, this translation system is inflexible in expression and influent in word order.

Beginning in 2016, traditional statistical machine translation has been gradually giving way to neural network machine translation. The traditional statistical machine translation is a phrase-based or hierarchical phrase-based translation. Its basic idea is to build a statistical translation model by a statistical analysis of many parallel corpus for translation, while the latest machine translation is an artificial neural network-based intelligent algorithm system which incorporates deep learning technology (ibid). The core of the technology is a deep neural network with massive nodes (neurons) that automatically learn translation knowledge from the corpus.

In recent years, intelligent translation technology has developed rapidly in China and has made some achievements. For example, in 2011, Baidu translation service was officially launched. In the same year, Netease's self-developed technologies-image processing, speech recognition, intelligent question and answer were applied and promoted in Youdao translation; in 2014 New Translation was established, together with its new products including intelligent translation system, document translation system, and auxiliary translation system, translation plug-in, intelligent translation APP, intelligent translation headset, multi-lingual intelligent robot, simultaneous conference system and other products, which can meet the multi-lingual conversion needs in different contexts; In early 2016, Tencent launched Tencent Mr. Translator, and On-line "simultaneous interpretation" product in the following year. In March 2018, Sogou introduced the smart Sogou Travel Translator.

Artificial intelligence translation is the integration of automatic computer translation and computer-aided translation. Artificial intelligence translation has been widely used and popularized because of its advantages of low cost, high degree of automation, fast translation speed, easy operation, and budget saving. 


\section{The characteristics of translation teaching at home and abroad in the context of artificial intelligence}

Many foreign universities offer students such translation education courses as introduction to corpus, multimodal and audiovisual translation, translation of science and technology, professional translation, translation project management, translation history, literary translation, interpretation research, sociology model of translation/interpretation, translation/interpretation teaching methods, etc.

Besides, there are also training modules for students, such as translations of scientific reports, popular science articles, health care documents, clinical case studies, user guides and technical specifications. A comprehensive reading list is available for each of the above specific area.

In order to improve translation quality and translation efficiency, students will learn translation software such as SDL Trados indispensable for professional translators, including translation memory programs and Multiterm management programs. Students need to learn translation memories, term-bases, workbench, alignment, SDL cloud technology and editors in Trados Studio 2015. At the same time, other translation software is available for students to choose, such as Transit, Across, MemoQ. After a systematic study of the translation software, students can master the basic skills professional translators should have, such as project management, translation memory, translation quality control or website localization.

In addition, the translation industry provides students with advice on how to start a career to help them better understand their future professions.

\section{The status quo of translation teaching at Chinese regional colleges and universities}

In view of the current situation of English translation teaching at local colleges and universities, Huang Shufang (2014) holds that the translation syllabus of local colleges and universities is out-of-date, the teaching approach simple, the teacher resource weak, cultural input inadequate, and thus students' learning output unsatisfactory.

Sui Yanna and Yao Minghui (2015) believe that teaching time is limited at local universities; the teaching content and materials are not updated; teachers' teaching ability is relatively weak, and there are insufficient opportunities to practice. Yuan Zhuoxi (2016) finds that the lack of teaching experience and teaching equipment poses many challenges for local universities and many efforts should be done to improve the current situation. Wang Shunlai (2016) says that the teaching concepts, teaching content and teaching methods should have innovative reforms based on the reality and characteristics of local universities.

In solving the problems, experts and scholars have studied and proposed suggestions from different perspectives such as teaching objectives, tasks, contents and teacher trainings. For example, Hu Weixia's task-based teaching methods, especially oriented to local industrial needs, are to cultivate translation talents to better serve local 
development (2015). Zhang Enhua (2016) proposed the necessity and practical plan for adopting the graded teaching mode. Wang Hua (2018) believes that English translation teaching activities should follow students' cognitive development. According to students' needs, teachers should work out teaching strategies, improve teaching and assessment methods, and pay attention to an experiential, interactive and creative translation teaching and learning process.

With the artificial intelligence technology booming, the innovation of translation teaching has been promoted. Many Chinese scholars began to emphasize the application of translation technology in translation teaching. Xu Bin (2006:59) introduced the concept and classification of computer-aided translation and discussed how to apply computeraided translation techniques to translation teaching in an effective way. Wu Yun (2006: 55) believed that computer-assisted translation software plays an important auxiliary role in translation teaching and mainly introduced the application of Trados in the teaching process. After a systematical review of the domestic research on computer-aided translation, Lv Lisong and Mu Lei (2007) introduced the current situation of computeraided translation teaching aboard, and made a proposal to the domestic universities to incorporate computer-aided translation technology into translation teaching. As regards the teaching of translation technology, Zhang Xiaojun proposed such suggestions as paying attention to the introduction of computer-aided translation software, increasing the projects for translation training, applying corpus in translation teaching, putting effort to cultivate teachers in translation technology, introducing and compiling textbooks on modern translation technology (Zhang Xiaojun, 2010). Zhang Xudong and Zhang Wei (2016) pointed out that translation has faced technical challenges. The translation market, translation process, and translation methods are all experiencing a certain degree of technical turn, thus requiring that university should adapt to the change quickly by training translation talents, adjusting curriculum of translation teaching and working on translation technology teaching. Zhang Ailing (2018) explored the path of the coupling mechanism between the development of artificial intelligence technology and professional oral translation practice. Qin Ying (2018) believes that translation teaching should focus more on technical techniques in the context of artificial intelligence to train higher-level translators faster and better, and to offer more courses on translation software to improve students' proficiency in translation software application.

It can be seen that domestic translation teaching, especially the translation teaching at local universities in China lags behind universities aboard in the application of translation technologies like Trados. Therefore, it is of great necessity to introduce translation teaching concepts, translation strategies and translation methods from overseas universities to Chinese translation teaching, so as to improve the quality of English translation teaching in local colleges and universities in the era of artificial intelligence. It should be advocated to make use of modern scientific and technological developments combined with network and digitalization to reform translation teaching content, mode and evaluation system, and to cultivate applied talents with solid theoretical foundation compatible with local economic development needs. 


\section{The Reform Path of Translation Teaching in Chinese Local Colleges under the Background of Artificial Intelligence}

\subsection{Changing traditional translation teaching concepts}

In the translation teaching under the background of artificial intelligence, the teacherstudent relationship is transformed from the traditional relationship of knowledge transferring and receiving to the present cooperative one. Teachers are no longer the leaders, but coordinators, collaborators, organizers and supervisors in the classroom learning and teaching activities in contrast with their traditional roles as commanders, controllers, judges, etc. Teachers guide students to screen and integrate relevant materials, stimulating students' interest and helping students to cooperate autonomously. And students become the main body in the teaching process, and their spontaneity and autonomy are improved as a result.

As important bases for the teaching process, teaching materials play important roles in ensuring good teaching results. As a result, the development of translation textbooks and materials should be based on the characteristics of local universities, with the consideration of the university's featured majors and the local socio-economic development. The translation textbooks and materials should include not only translation theories and strategies, but the artificial intelligence translation technologies. Therefore, in classroom teaching, the effective combination of traditional translation theories, skills with translation technologies provide students with both theoretical and practical bases, realizing "integration of knowledge and action."

\subsection{Cultivating teachers' comprehensive professional quality}

As a qualified translation teacher, one must first have a good professional quality, including translation teaching concepts and skills, translation professionalism, translation theories and research capabilities.

In the era of artificial intelligence, translation teachers should not cling to the obsolete traditional teaching concepts but carry the modern teaching thought of cultivating students' information literacy through the whole process of translation teaching. Teachers should completely change their roles and explore the characteristics and new modes of task-based, cooperative, and autonomous translation teaching in the time of artificial intelligence, promoting the reform and development of translation teaching in the new environment.

$\mathrm{Mu}$ Lei et al. (2013) believed that the translation profession for translator teachers includes occupational features and laws, professional regulations and ethics. Only when teachers have a good command of translation theories and techniques, and a good knowledge of the characters, norms and standards of translation profession, operational procedures, and market needs can they cultivate students' professional qualities by their words and deeds.

Translation teachers should not only have a good knowledge of translation theory, a keen insight into the development of translation studies at home and abroad, rich 
experience in translation practice, but also be able to apply theory to practice and constantly sublimate theories in practice to promote teaching and research.

Teachers should also take the initiative to participate in scientific research activities and teams, apply for teaching and research projects, and attend teacher training courses, lectures and seminars, which therefore help them strengthen their cooperative learning ability, understand the knowledge and scientific research progress in this field and improve their scientific research capabilities.

In the era of artificial intelligence, translation activities rely more on translation technology. Therefore, professional teachers in translation must have good information literacy. Teachers' information literacy is characterized by a systematic mastery of information theory and such abilities as information resource retrieval, analysis, practice, operation and integrating information technology and curriculum, etc. (He Hongli, 2015) With a good mastery of information teaching skills, English translation teachers can carry out scientific research and guide students in translation practices. However, at present, college translation teachers are facing the difficulties of lacking theoretical knowledge and practical experience concerning information technology, being incompetent in applying information technology to translation courses, and enjoying insufficient training opportunities and recourses on translation information technology.

To solve the problems, schools and education departments should make greater efforts to increase investment and carry out special teacher training courses to improve teachers' skills in translation technology, and effectively ensure the quality and result of translation teaching.

\subsection{Establishing intelligent translation teaching platform}

In the artificial intelligence environment, translation information technology will by no means surpass or replace the translation teaching mode but complement and optimize it. Translation teaching in the new environment focuses more on individualization, humanization, intelligence and diversification and can realize self-exploration learning, collaborative learning, resource sharing, situation creation, information acquisition, and cross-regional synchronous teaching activities.

In the intelligent teaching process, teachers use a variety of learning software and resources to enrich the content of the curriculum and to increase the depth and breadth of knowledge, improving the effectiveness and efficiency of teaching, and enhancing students' learning initiative; teachers can provide students with a wide range of online learning resources to study in and after class, such as Mooc, Micro-courses, online courses, WeChat learning platforms and other online learning approaches, which are more humane ways for the one-to-one online interactions and Q\&A between students and teacher.

At the same time, data can be effectively tracked, and students' learning process, task completion and learning effects can be well monitored. Teachers therefore can make appropriate interventions to improve students' academic performance. Students can also 
monitor and supervise themselves through the online platform, thus discovering problems in learning and correcting them in time.

Artificial intelligence also provides an accurate assessment of teaching and learning. Based on the combination of structural assessment and indicator assessment, the whole teaching ecology is dynamically evaluated and can better embody the essence of formative evaluation of students' learning more scientifically and objectively, providing references and guidance for the next round of teaching and learning (Hong Changchun, 2018).

Intelligent evaluation is also capable of discovering the blind spots, difficulties, key points, easy points and repeated content in learners' translation learning, thereby accurately matching resources, formulating personalized learning programs, saving learners' time and improving learning effectiveness.

\section{Conclusion}

The integration of artificial intelligence technology into translation teaching activities is the inevitable result of the development of the times. The use of artificial intelligence can improve students' learning experience and learning efficiency and help translation teachers to carry out innovative research on translation teaching. The application of artificial intelligence in the field of translation is now making contribution to the field of translation and creating an unprecedented prospect as well.

\section{References}

He, Hongli (2015). Analysis on the Ways of Translation Teachers' Professional Development in the Big Data Era. Journal of Changzhi University, (6): 83-86.

He, Liubo (2018). Reflections on the development of computer aided translation in China under the background of artificial intelligence. English Square, (5): 17-19. DOI:10.16723/j.cnki.yygc.2018.05.007

Hong, Changchun (2018). Students' Online Learning and Course Evaluation: A Case Study of Advanced English Course. Technology Enhanced Foreign Language Education, (6):29-33.

$\mathrm{Hu}$, Weixia (2015). Research on the teaching status and countermeasures of business English translation courses in local colleges and universities. Journal of Xingtai University, (2):141-143.

Huang, Shufang (2014). Research on digital publishing of college English translation textbooks. Overseas English, (6): 149-150, 159.

Liang, Jianwei (2018). Promoting the development of intelligent translation industry to help artificial intelligence industry flourish in Guangdong. Guangdong Economy, (9): 40-45. 
Lv, Lisong, Mu Lei (2003). Computer-aided translation technology and translation teaching. Foreign Language World, (3): 35-43.

Ministry of Education of the People's Republic of China, Education Informatization 2.0 Action Plan, retrieved Apr. 2018, from http://www.moe.gov.cn/srcsite/A16/s3342/201804/t20180425 334188.html.

Ministry of Education the People's Republic of China. Innovative Action Plan for Artificial Intelligence in Colleges and Universities, retrieved Jun. 2018, from http://www.moe.gov.cn/srcsite/A16/s7062/201804/t20180410 332722.html?from= groupmessage\&isappinstalled $=0$.

Ministry of Industry and Information Technology. Three-Year Action Plan for Promoting the Development of a New Generation of Artificial Intelligence Industry (20182020), retrieved Dec 2017, from http://www.miit.gov.cn/n1146295/n1652858/n1652930/n3757016/c5960820/content .html.

Mu, Lei et al. (2013). The improvement of the training mechanism of professional translation talents from the angle of professionalization, Foreign Languages in China, (1): 85-95. DOI:10.13564/j.cnki.issn.1672-9382.2013.01.002

Qin, Ying (2018). An Analytical Study of Neural Network Machine Translation and Its Impacts on Translation Teaching. Technology Enhanced Foreign Language Education, (2): 51-56.

State Council of the People's Republic of China. The Development Plan of the New Generation Artificial Intelligence, retrieved Jul. 2017, from http://www.gov.cn/zhengce/content/2017-07/20/content 5211996.htm.

Sui, Yanna, Yao Minghui (2015). A brief analysis of the problems and countermeasures in English translation teaching in local colleges and universities. Innovation Education, (12):121.

Wang, Hua (2018). An analysis of college English translation teaching from the perspective of cognitive linguistics. Education Modernization, 5(31):148-149. DOI: 10.16541/j.cnki.2095-8420.2018.31.065.

Wang, Shunlai (2016). On the transformation of translation talents training in local colleges and universities. Journal of Henan Institute of Science and Technology, (6): 1416. doi: 10.3969/j.issn.1673-6060.2016.06.004.

$\mathrm{Wu}$, Yun (2006). The pedagogical use of online cobuild concordance and collocation sampler. Technology Enhanced Foreign Language Education, (06):56-58, 69.

$\mathrm{Xu}, \mathrm{Bin}(2006)$. CAT and translation research and teaching, Shanghai Journal of Translators, (4):59-63.

Yuan, Zhuoxi (2016). A brief analysis of the problems and countermeasures in English translation teaching in local colleges and universities. Journal of Lanzhou Institute of Education, (3):102-103.

Zhang, Ailing et al. (2018). A Tentative Proposal for Translation \& Interpreting Based on Human-Computer Collaboration through Developments in Artificial Intelligence. Technology Enhanced Foreign Language Education, (3):88-93. 
Zhang, Enhua (2016). Practical research on graded teaching of English translation courses in local colleges and universities, Journal of Jiamusi Vocational College, (7): 306.

Zhang, Xiaojun (2010). Translation technology teaching in British universities and its enlightenment. Foreign Language Research, (6):76-79

Zhang, Xudong, Zhang Wei (2016). A review on the technical tendency of translation. Foreign Languages Research, (5):88-91. 
Ma, Yan; Wang, Feng

PRACTICE OF INFORMATION TECHNOLOGY IN TRANSLATION TEACHING AT CHINESE REGIONAL UNIVERSITIES IN THE ERA OF ARTIFICIAL INTELLIGENCE

Creative Commons licensing terms

Author(s) will retain the copyright of their published articles agreeing that a Creative Commons Attribution 4.0 International License (CC BY 4.0) terms will be applied to their work. Under the terms of this license, no permission is required from the author(s) or publisher for members of the community to copy, distribute, transmit or adapt the article content, providing a proper, prominent and unambiguous attribution to the authors in a manner that makes clear that the materials are being reused under permission of a Creative Commons License. Views, opinions and conclusions expressed in this research article are views, opinions and conclusions of the author(s). Open Access Publishing Group and European Journal of Education Studies shall not be responsible or answerable for any loss, damage or liability caused in relation to/arising out of conflicts of interest, copyright violations and inappropriate or inaccurate use of any kind content related or integrated into the research work. All the published works are meeting the Open Access Publishing requirements and can be freely accessed, shared, modified, distributed and used in educational, commercial and non-commercial purposes under a Creative Commons Attribution 4.0 International License (CC BY 4.0). 